\title{
Program för social- och hälsopolitik
}

Sveriges ordförandeskap 2018

10 Nordiska ministerrådet 
Program för social- och hälsopolitik

Sveriges ordförandeskap 2018 i Nordiska ministerrådet

ANP 2017:789

ISBN 978-92-893-5298-7 (PRINT)

ISBN 978-92-893-5299-4 (PDF)

ISBN 978-92-893-5300-7 (EPUB)

http://dx.doi.org/10.6027/ANP2017-789

(c) Nordiska ministerrådet 2017

Layout: Louise Jeppesen

Omslagsfoto: unsplash.com

\section{Det nordiska samarbetet}

Det nordiska samarbetet är ett av världens mest omfattande regionala samarbeten. Det omfattar Danmark, Finland, Island, Norge och Sverige samt Färöarna, Grönland och Åland.

Det nordiska samarbetet är politiskt, ekonomiskt och kulturellt förankrat och en viktig del av europeiskt och internationellt samarbete. Den nordiska gemenskapen arbetar för ett starkt Norden i ett starkt Europa.

Det nordiska samarbetet vill styrka nordiska och regionala intressen och värderingar i en global omvärld. Gemensamma värderingar länderna emellan bidrar till att stärka Nordens ställning som en av världens mest innovativa och konkurrenskraftiga regioner.

\section{Nordiska ministerrådet}

Nordens Hus

Ved Stranden 18

1061 København K

www.norden.org

Ladda ner nordiska publikationer: www.norden.org/nordpub 


\section{Program för social- och höllsopolitik}

\section{Svèriges ordförandeskap 2018 \\ i Nordiska ministeŕro̊det}

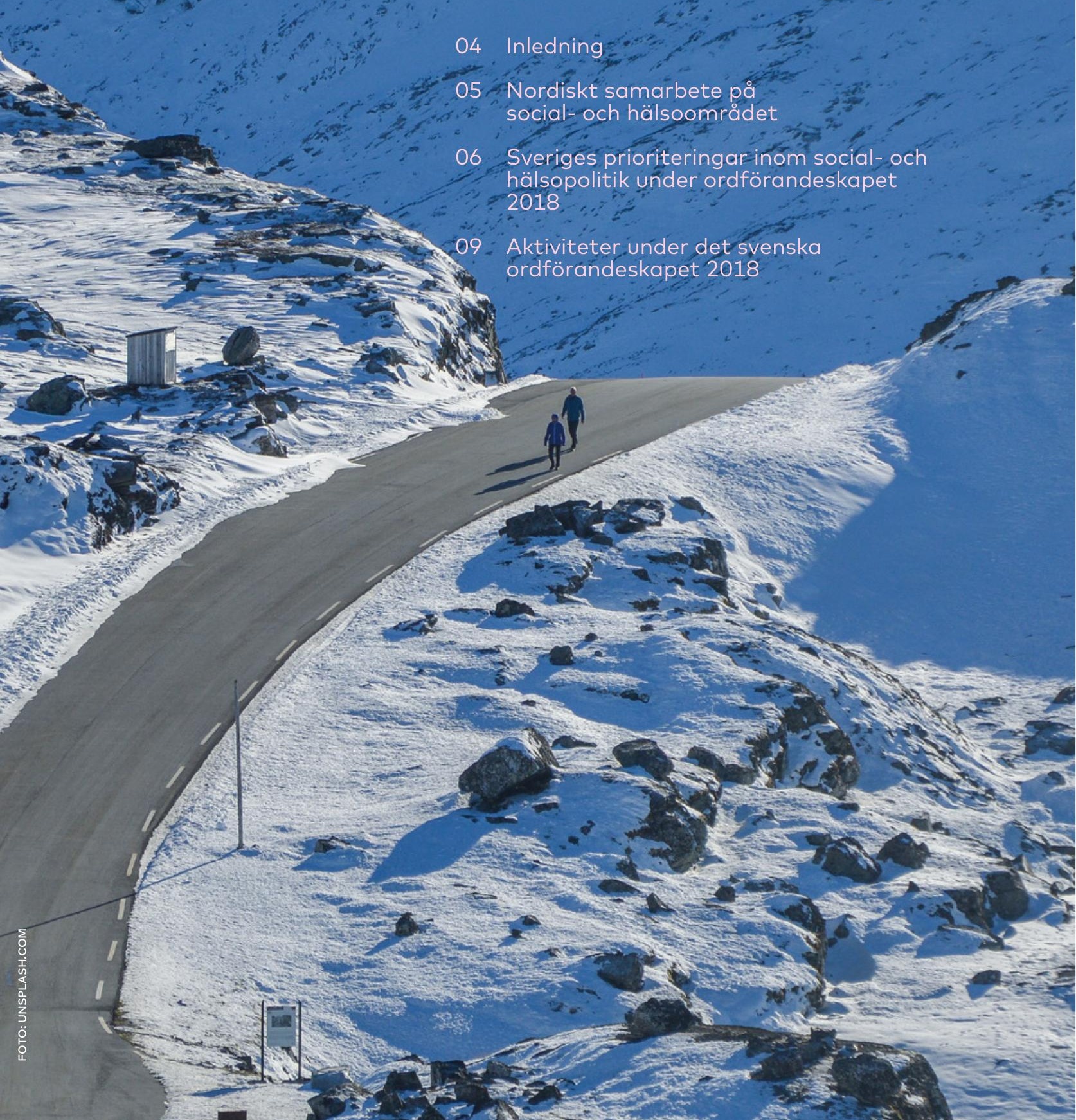


Under 2018 är Sverige ordförande i Nordiska ministerrådet. Ett inkluderande, hållbart, innovativt och tryggt Norden är utgångspunkten för Sveriges ordförandeskapsarbete genom vilket temat digitalisering samtidigt löper som en röd tråd. Inom sektorprogrammet för socialoch hälsopolitik kommer Sveriges ordförandeskap i sina aktiviteter att särskilt fokusera på temat äldre och en åldrande befolkning med de utmaningar för sjukvård och omsorg som detta medför.

Jämställdhet beaktas i alla aktiviteter som kan bidra till jämställd välfärd alternativt ökad jämställdhet i hälso- och socialpolitik. Därutöver kommer man inom det nordiska ämbetsmannasamarbetet och ministermötet att fokusera på att utveckla samarbetet på det socialpolitiska området. 


\section{Nordiskt samarbete på social- och hälsoområdet}

De nordiska regeringarnas samarbete på social- och hälsoområdet leds av Ministerrådet för social- och hälsopolitik (MR-S). Detta samarbete är förankrat i de nordiska ländernas gemensamma värderingar som den nordiska välfärdsmodellen bygger på. Det nordiska samarbetet inom social- och hälsosektorn har också stor betydelse för att uppnå FN:s globala mål inom Agenda 2030.

Principerna i välfärdssamhället i Norden grundar sig på alla medborgares lika möjligheter samt social solidaritet och trygghet för alla oavsett kön, etnisk tillhörighet, religion, övertygelse, funktionsnedsättning, ålder och sexuell läggning. I praktiken handlar det om sociala rättigheter och att alla ska ha lika tillgång till hälso- och sjukvårdstjänster samt till sociala tjänster, utbildning och kultur. Det gäller också omsorgen för socialt utsatta och sårbara grupper i samhället.
Det nordiska samarbetsprogrammet på social- och hälsoområdet för perioden 2017-2020 fokuserar på fyra specifika mål som ska stärka hållbar välfärd och hälsa i Norden:

- Främja välfärds- och hälsopolitik som säkrar social trygghet på en föränderlig arbetsmarknad, inkluderar utsatta grupper samt förhindrar social exkludering.

- Främja en målinriktad och effektiv resursinsats på social- och hälsoområdet som i högre grad möter framtidens behov. Förebyggande, tidiga insatser och rehabilitering ska prioriteras.

- Höja kvalitet och säkerhet inom hälso- och sjukvård, omsorgs- och välfärdstjänster.

- Främja innovation och forskning om framtidens hälso- och sjukvård samt omsorgs- och välfärdstjänster. 


\section{Sveriges prioriteringar inom social- och hälsopolitik under ordförandeskapet 2018}

Med utgångspunkt i dessa långsiktiga målsättningar har det svenska ordförandeskapet i Nordiska ministerrådet för social- och hälsopolitik 2018 valt att i sitt program prioritera följande teman och aktiviteter.

\section{Kvalitet i äldreomsorgen och bättre arbetsmiljö}

Ett exempel på aktivitet inom fokusområdet äldrefrågor är den konferens på temat Att arbeta inom äldreomsorgen som arrangeras under året. En del av syftet är att lyfta fram och belysa brister i arbetsmiljön, som t.ex. stress och hög arbetsbelastning för personalen. Men det primära syftet är att inspirera och visa på förändringsarbete som kan leda till bättre arbetsmiljö, göra yrket mer attraktivt, öka trivsel och hälsa hos personal och därmed också kvaliteten i omsorgen om de äldre.

\section{Prioriteringsprojekt för innovativa servicelösningar och vård på distans}

De nordiska länderna står inför gemensamma utmaningar i form av en åldrande befolkning och en alltmer avfolkad landsbygd som gör att behovet av distanslösningar för vård och omsorg sannolikt kommer att öka framöver.
Det är därför viktigt att ta tillvara den potential som finns i Norden och motverka ökad regional obalans, samtidigt som ekonomisk tillväxt, befolkningsutveckling och service främjas. Det behövs innovativa servicelösningar och modeller för att hantera demografiska utmaningar utifrån regioners och samhällens olika förutsättningar och då särskilt på landsbygden. Nya sätt att leverera välfärdstjänster är en möjlighet. Distanslösningar för vård och omsorg måste dock ses som ett komplement och inte som en ersättning för fysisk kontakt med dessa tjänster.

Inom det nordiska samarbetet har ordförandelandet tillgång till en särskild nordisk budget för att initiera och driva särskilt prioriterade aktiviteter. Ett av fyra sådana stora projekt som Sverige påbörjar under 2018 är Utvecklade lösningar för vård på distans och e-recept över landgränser med en budget på 12 miljoner DKK fördelad över tre år. Ett delmål för projektet är att inom en treårsperiod ha tekniska förutsättningar på plats för utbyte av e-recept i Norden. 


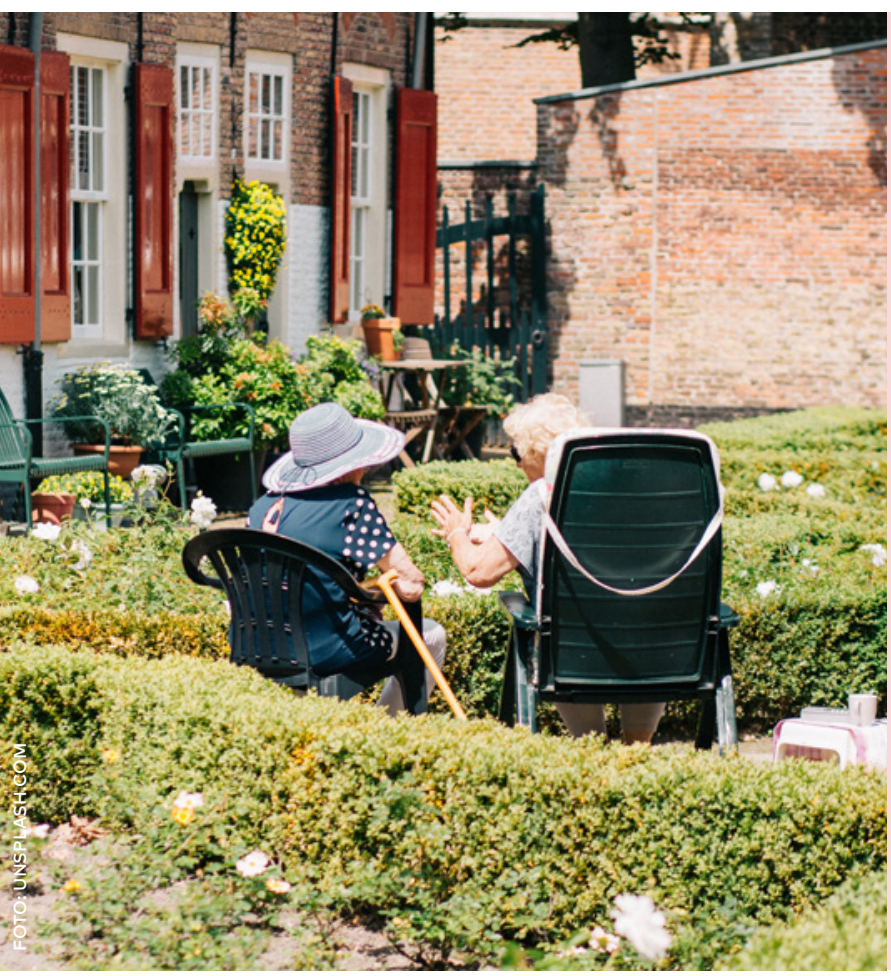

Samarbetet inom Nordiska ministerrådet syftar till att främja rörligheten mellan de nordiska länderna och att utveckla det nordiska välfärdssamhället i ett europeiskt perspektiv. Vidare är arbetet inriktat mot att utveckla Nordens samarbete med regionens närområden samt att utbyta erfarenheter och nationell information. Nordisk nytta är en grundläggande princip för samarbetet.

\section{Genomlysning av} det socialpolitiska området

De nordiska social- och hälsoministrarna i MR-S beslutade i mars 2017 att be generalsekreteraren genomföra en strategisk genomlysning av det nordiska samarbetet på det sociala området. Detta efter att det tidigare hade genomförts en motsvarande genomlysning med fokus på det nordiska samarbetet inom hälsoområdet. Målsättningen med den nya genomlysningen är att utveckla och stärka samarbetet på det sociala området på ett sätt som är anpassat till ländernas behov och aktuella problemställningar samt så att det leder till konkreta resultat. Meningen är att genomlysning- en ska ta utgångspunkt i och utveckla den nordiska välfärdsmodellen och bland annat ha fokus på huruvida investeringar i sociala aktiviteter och tjänster kan bidra till att tillmötesgå samhälleliga utmaningar. Resultaten kommer att presenteras under det svenska ordförandeskapsåret efter att ha diskuterats vid nordiska social- och hälsoministrarnas möte i mars 2018. Det blir sedan en del av Sveriges ordförandeskapsarbete att styra upp och konkretisera det nordiska samarbetet kring de förslag som framkommer i genomlysningens slutrapport. 


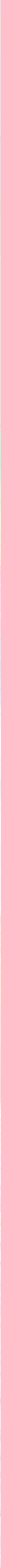




\section{Aktiviteter under det svenska ordförandeskapet 2018}

På www.regeringen.se/norden 2018 publiceras löpande uppdaterad information om ordförandeskapets aktiviteter.

\section{MÖTEN I MINISTERRÅDET FÖR SOCIAL- OCH HÄLSO- POLITIK (MR-S) OCH ÄMBETSMANNAKOMMITTÉN FÖR SOCIAL- OCH HÄLSOFRÅGOR (ÄK-S)}

9 februari

22 mars

14-15 juni

15-16 november
ÄK-S (1) samlas till sitt första möte under året

Kvällen innan mötet, den 14 februari, bjuder Sveriges ordförandeskap i Nordiska ministerrådets 2018 in ÄK-S delegationerna och Nordiska ministerrådets sekretariat till mottagning på Sveriges ambassad i Köpenhamn. Därefter blir det en nätverksmiddag. Adresser och tidpunkt kommer att meddelas i kallelse till ÄK-S mötet.

Plats: Köpenhamn

MR-S samlas till sitt årliga möte

Plats: Uppsala

ÄK-S (2) samlas till sitt andra möte under året

Plats: Ystad

ÄK-S (3) samlas till sitt tredje möte under året

Plats: Göteborgsregionen 


\section{PROJEKT, MÖTEN, SEMINARIER OCH KONFERENSER}

mars/april

Högnivåmöte för nordiska departements-/ avdelningschefer inom hälsovårdsområdet

Under perioden 2018-2020 kommer årliga högnivåmöten att hållas med målsättning att utveckla nätverket och stärka dialogen mellan de högsta ansvariga cheferna inom social- och hälsovårdsområdet i ländernas departement. Först ut blir detta möte för cheferna inom hälsovårdsområdet.

Plats: Stockholmsregionen

20 april

Att arbeta inom äldreomsorgen

Konferens om arbetsmiljö, kvalitet och jämställdhet i äldreomsorgen.

Den viktigaste resursen i äldreomsorgen är personalen varav 90 procent är kvinnor. Brister som stress, hög arbetsbelastning och för liten tillgång till chefer gör att många vill sluta, att sjukskrivningstalen är höga och att kommunerna får svårt att rekrytera och behålla personal.

Konferensens syfte är att synliggöra de problem som finns samt visa på olika sätt att stödja en positiv utveckling. Konferensen kommer att rikta sig till beslutsfattare på nationell, regional och lokal nivå, till myndigheter, kommun- och regionförbund samt professions-, pensionärs- och brukarföreträdare.

Plats: Stockholm 


\section{Vård och omsorg i förändring}

Konferens om hur de demografiska utmaningarna med åldrande befolkningar ökar behovet av vård och omsorg i de nordiska länderna, och hur innovationer och organisatoriska förändringar kan vara en del av arsenalen av åtgärder för att möta de växande behoven.

Med modern informationsteknik kommer demografiska prognoser att gestaltas och företeelser som e-hälsa och mobil hälsa kommer att behandlas. Förstatligandet av det norska sjukhusväsendet vid början av 2000 talet kommer att belysas och genomförda danska kommun- och regionreformer kommer att presenteras. En planerad finsk reform av hela vård- och omsorgssektorn kommer att vara ett inslag, och det blir tillfällen till erfarenhetsutbyte mellan konferensdeltagarna.

\section{Plats: Malmö}
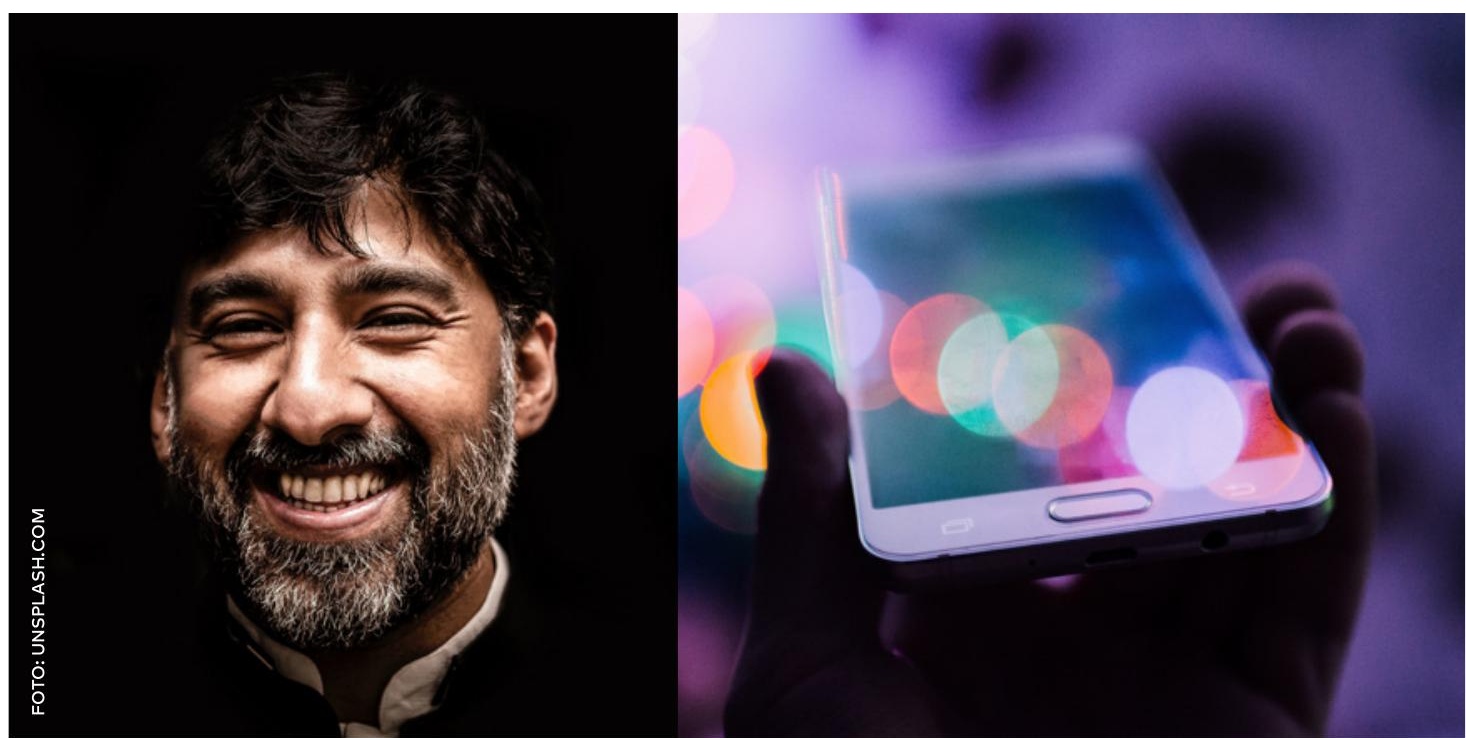


\section{Aktivitet angående nordisk jämförande}

studie: Nordiska pensionsgapen -

jämställda pensioner

Ojämlikt arbetskraftsdeltagande och skilda lönenivåer för män och kvinnor leder till ett inkomstgap mellan könen under förvärvslivet. Med inkomstbaserade pensionssystem som bygger på eget intjänande, fortplantar sig orättvisor in i pensionärslivet med ojämlika pensioner. I grunden är det ett strukturellt problem under förvärvslivet men åtgärder kan vidtas för att minska gapen.

Under ordförandeskapet kommer Sverige att ta initiativ till en nordisk studie som ska ligga grund för ett fortsatt arbete för jämställda pensioner i Norden. Målsättningen blir bland annat att:

- diskutera en framtida gemensam standard för att beräkna och jämföra pensionsgapet i de nordiska länderna med möjlighet att kunna följa dessa över tiden

- utbyta erfarenheter och idéer av åtgärder som minskar gapet

- få ett större fokus och uppmärksamhet på problematiken och sporra till förbättringar

- åstadkomma ett större tryck för mätningar av gapet och åtgärder för att minska det.

Plats: Stockholm 
november

\section{Nordisk e-hälsosamling}

De nordiska ländernas hälso- och sjukvårdssystem har många likheter i grunden. Ett verksamhetsfält som diskuterats på olika nivåer sedan ett antal år tillbaka är e-hälsoområdet. Alla nordiska länder gör olika insatser, och denna samling blir en möjlighet att mötas kring aktuella frågor i den nordiska kontexten. Förslaget är att möten sker på flera ställen utspritt i landet under en vecka för att få med olika regionala aktörer som arbetar med prioriteringsprojektet rörande distansvård och e-recept, bland annat Glesbygdsmedicinskt centrum i Storuman.

Plats: Stockholm samt en eller två ytterligare orter

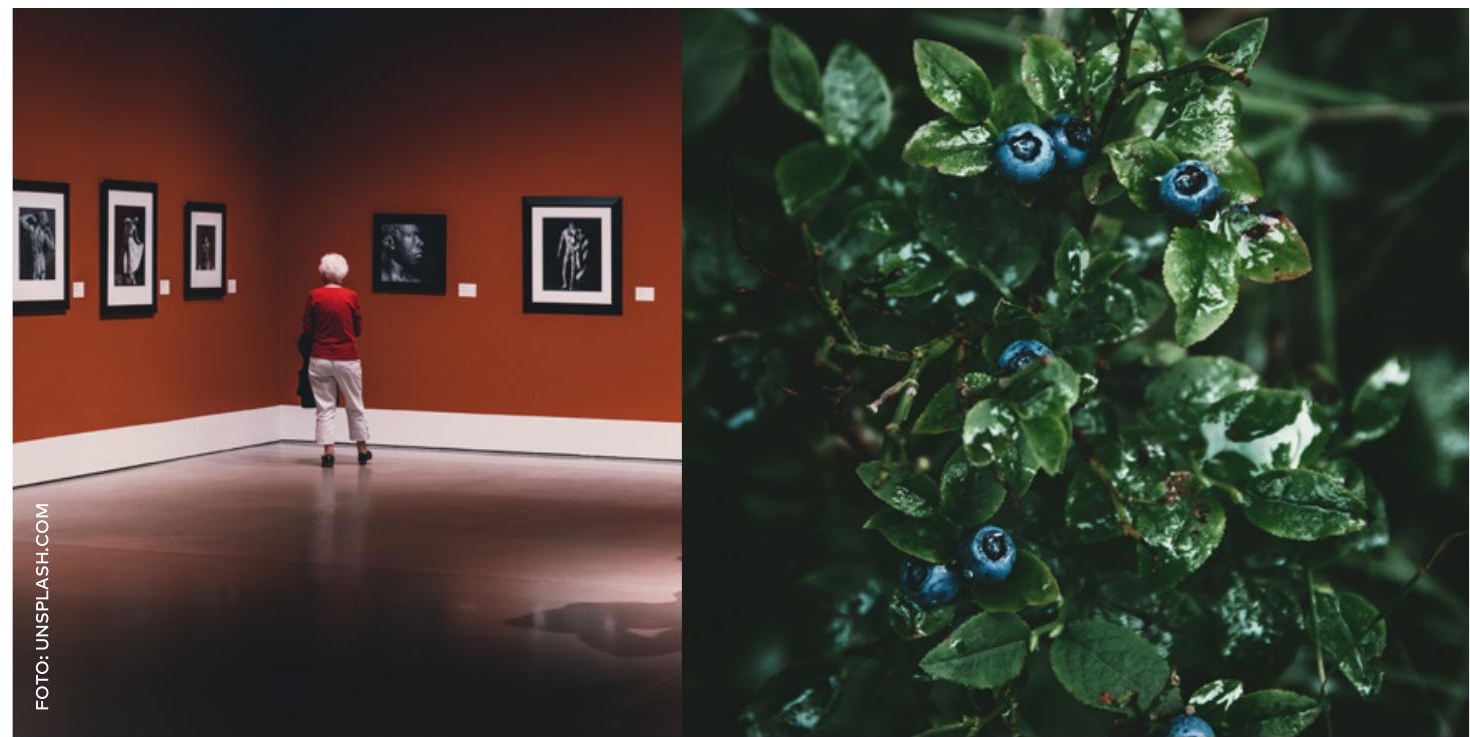




\title{
AKTIVITETER OCH PROJEKT SOM YTTERLIGARE PLANERAS ATT GENOMFÖRAS UNDER HÖSTEN 2018
}

\section{Uppstart för projekt om nordiskt nätverk för åldervänliga städer}

Ett initiativ under Sveriges ordförandeskap 2018 i samverkan med FN:s Världshälsoorganisation (WHO), Nordens välfärdscenter (NVC) och Nordiska ministerrådets sekretariat för att anordna en uppstartskonferens med målsättning att utveckla ett nordiskt nätverksarbete för åldervänliga städer inom WHO:s globala nätverk Age Friendly Cities inom vilket cirka 350 städer i världen samverkar.

Plats: Stockholm

\begin{abstract}
Aktivitet tillsammans med Nordens välfärdscenter
Aktivitet eller resurs rörande folkhälsa/jämlik hälsa i samband med Nordens välfärdscenters övergripande arrangemang under hösten för att presentera Folkhälsoarenans arbete och projekt.
\end{abstract}


Nordiska ministerrådet

Nordens Hus

Ved Stranden 18

DK-1061 Köpenhamn K

www.norden.org

ANP 2017:789

ISBN 978-92-893-5298-7 (PRINT)

ISBN 978-92-893-5299-4 (PDF)

ISBN 978-92-893-5300-7 (EPUB) 